\title{
Research on Price Effects of SPS: Based on Tea Trade of Japan
}

\author{
Jiang Tao ${ }^{\text {a }}$, Yaokui Wang * \\ China Jiliang University, Hangzhou 310018, China \\ ajtqqx@yahoo.com.cn,*Corresponding author Email:tjcuwyk@126.com
}

\begin{abstract}
Using tea trade panel data on the main imported countries of Japan, the paper analyses the price effects by SPS on imported tea of Japan. The Japanese Positive List System (PLS) had a profound impact on the price of Japan imported tea. Furthermore, we draw the conclusion that the promulgation of PLS improve the price of imported tea, while the implementation of PLS hinder the price. The price effects of PLS is helpful to the exporters to cope with the technical barriers of trade.
\end{abstract}

Keywords: Sanitary and Phytosanitary Measures; Tea trade; Price effects.

\section{Introduction}

Considering of complexity and hidden features of Sanitary and Phytosanitary Measures (SPS), which is increasingly becoming one of the most difficult barriers to deal with international trade, especially posing a serious challenge in the export of agricultural exporting developing countries. In fact, the impact of SPS on trade is reflected in two aspects, volume and price, the former called trade effect, and the latter is called the price effect. The price effect further reflects signal of product quality and function of cost transforming, which reduces the negative impact of SPS on the export enterprises through quality improvement and price promotion. With the help of SPS, that provides an important approach to deal with accelerating the export transformation and upgrading. However, the existing literature pays more attention to trade effects of SPS than those of SPS (Wilson Otsuki, 2004; Gebrehiwet et al, 2007; Chert, Yang \& Findlay, 2008). Therefore, this article is intended to the price effects of Japanese Positive List System (PLS), using the time serial data analyzing the price effect, the data from five major Japanese tea trade exporter (including Chinese, Sri Lanka, India, Indonesia and Kenya), observing discrepancy of the impact of PLS System promulgation and formally implemented on tea import prices.

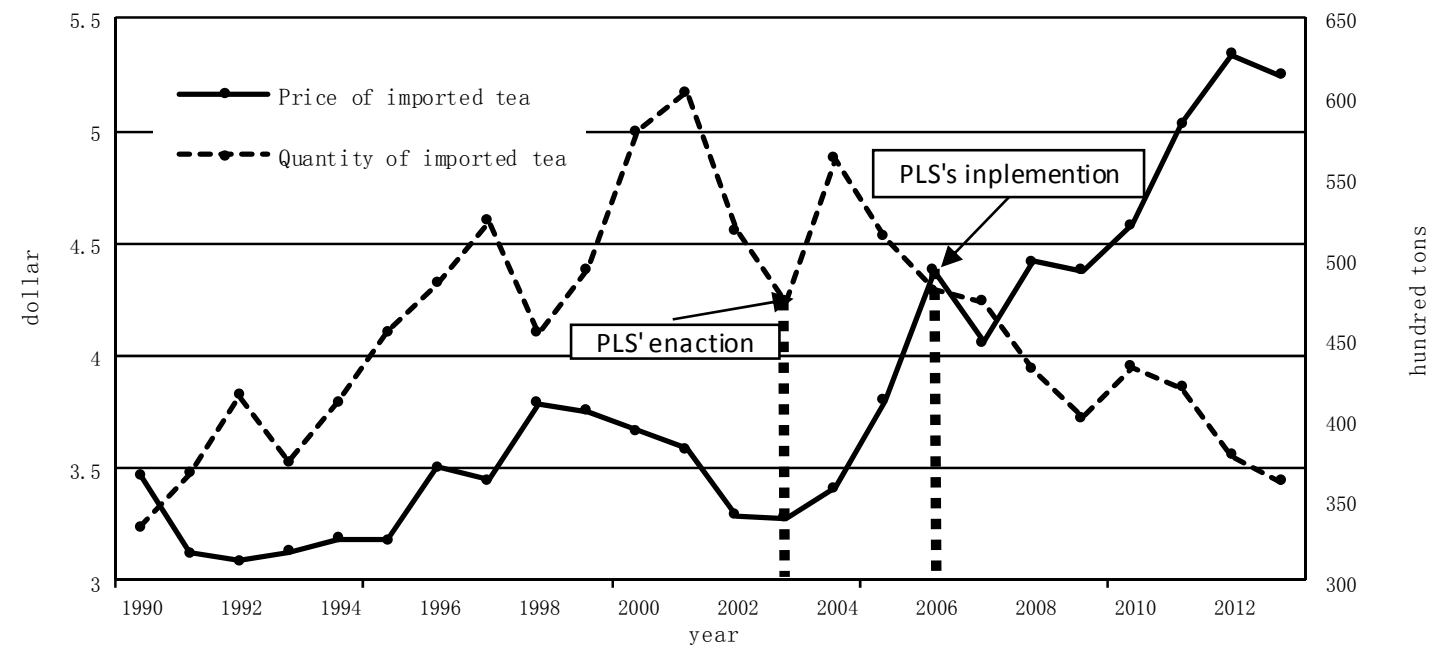

Fig. 1 tea importing data of Japan

PLS system is mandatory technical regulations. Compared with the original regulations, PLS system requires a more comprehensive, systematic and rigorous on food agricultural chemical residual limit. The system improves agricultural products quality threshold in Japanese importing agricultural products, to a certain extent, limits the import of agricultural products, and weakens competition of the domestic market. Tea is one of Japan's major imports of agricultural products are 
also severely impacted by PLS system. Since 2005, Japan enacted the PLS system and officially implementation in 2006, there is a clear downward trend the total tea imports from the five countries. At the same time, the corresponding tea CIF price is showing a clear upward trend, as shown in Figure.1.

Under the double impact of quality improvement and competitiveness weakened, there is upward momentum in Japanese market consistent with the presence of tea quality requirements PLS import prices. However, once a large number of enterprises make a breakthrough from PLS system in the technology, which requires resuming exports to Japan. The Japanese import market will tend to be competitive, tea import prices up warding momentum may be inhibited in some degree. So, as reflected in Figure 1, the volatility and rising import prices of Japanese tea market are affected by PLS institutional constraints? In this paper, based on importing tea panel data, introducing controlling factors, concentrating study price effects of tea imports caused by PLS system.

\section{Literature Review}

Existing SPS research literature focuses on the trade effects, Extensive literature using many methods to measures the effects of SPS, such as, gravity model, tariff equivalent method, coverage and frequency ratios and so on. (Beghin \& Bureau, 2001; James Anderson \& Eric van Wincoop, 2003; Lan \& Yue, 2009).The former measure the relationship among macro trade and GDP, distance and other variables by the traditional gravity equation; the latter forces the gravity model that representative consumer individual decision based on equilibrium (James Anderson \& Eric van Wincoop, 2003). Tariff equivalent method, convert SPS to equivalent effect of tariffs, in order to assess their impact on trade (Calvin \& Krissoff, 1998;. Yue et al, 2006; Lan \& Yue, 2009). The tariff equivalent method can be subdivided into homogenous tariff equivalent method, heterogeneous tariff equivalent method and dynamic and heterogeneity tariff equivalent method. Coverage and frequency ratio are commonly methods to measure SPS (Henry \& Vancauteren, 2006; Disdier et al, 2008; Bao Xiaohua and Zhong Zhudi, 2006; Bao Xiaohua, 2010; Tian Dongwen and Yao Wei, 2012). Coverage ratio refers to the ratio of non-tariff barriers on given set of implementation products, according to the trade flows broken down into import and export coverage. Frequency coverage ratio is similar to coverage ratio.

Relevant literatures of price effects SPS are lack. Considering tariff equivalent method of microdecisions optimization ideological construction of the theoretical basis of empirical research. This paper from typical household spending decisions deduced balanced equation about tea import prices and spending, demand and other variables, with the balanced equation, expanding the corresponding econometric model to measure the price effect of SPS.

\section{Construct Theoretical Models}

This paper Based Yue's (2009) microdecision analysis framework, proposing equilibrium equation that from the individual optimal decision containing SPS price effect, reflecting Japan's leading domestic tea consumption. Suppose a typical Japanese household consumption of domestic and imported two types of tea, including the demand for the domestic tea by $\mathrm{D}$, and the demand for imports of tea by I. The family needs to bear part of the cost affected by PLS system in the consumering importing tea. The cost passes on in the form of price-expressed, suppose bear the share borne by households. Thus, the typical family of tea consumption decisions basic analytical framework as follows:

$$
\begin{aligned}
& \underset{D, I}{\operatorname{Max}} U(D, I)=\left[D^{\rho}+I^{\rho}\right]^{1 / \rho} . \\
& \text { s.t.? } P_{D} D+\left(1+c_{p l s}\right) P_{I} I=M+M^{\prime}
\end{aligned}
$$

Among them, $\mathrm{M}$ a typical total household spending on these two types of tea, while the total xpenditure on other projects; additional family expenses caused to PLS system, and are domestic and 
imported tea, tea prices, the elasticity of substitution, the calculations can be Marshall was imported tea demand function expression:

$$
P_{I}=\frac{M+M^{\prime}}{\left(1+c_{p l s}\right)+\left(1+c_{p l s}\right)^{\sigma}\left(\frac{D}{I}\right)^{\rho}} I .
$$

Formula (3) reflects the equilibrium relationship between the Japanese home total tea imports prices and household spending, imports, domestic demand, PLS transfer costs triggered by other factors. Simplicity, we tend to get the price of imported tea functional relationship, such as formula (4)

$$
P_{I}=f\left(M+M^{\prime}, D, I, c_{p l s}\right) \text {. }
$$

Based on the further build the formula (4) tea trade price regression model, the following form:

$$
\ln P_{i t}=\alpha+\beta_{1} S P S_{1 t}+\beta_{2} S P S_{2 t}+\beta_{3} S P S_{2 t} \cdot \ln Q_{i t}+\beta_{\mathrm{i}} \ln \text { Control }_{i t}+\mu_{i t}
$$

In formula (5), the dependent variable $\ln$ Pit for the Japanese tea CIF price of imported natural logarithm. Explanatory variable SPS1t is a dummy variable for PLS enacting node, and SPS2t is a dummy variable for PLS implementing node. Among them, the year 2003 was enacted PLS system node; and the year 2006 was implemented node.

$$
\begin{aligned}
& S P S_{1 \mathrm{t}}=\left\{\begin{array}{ll}
1 & \mathrm{t} \geqslant 2003 \\
0 & \mathrm{t}<2003
\end{array} .\right. \\
& S P S_{2 \mathrm{t}}=\left\{\begin{array}{ll}
1 & \mathrm{t} \geqslant 2006 \\
0 & \mathrm{t}<2006
\end{array} .\right.
\end{aligned}
$$

Adding cross-termSPS $2 \mathrm{t} * \ln Q_{\mathrm{it}}$ in formula (5), which represents the amount of impact on the price of tea imported under the PLS conditions for implementation. We also increase the number of control variables GDP, CPI, exchange rates, the countries total trade, trade in tea and so on

\section{Empirical Analysis}

Data and variables Selecting. Further to the above-mentioned tea trade price regression model are explained and explanatory variables described in detail. The dependent variable for the Japanese tea imports CIF price; control variables include Japanese GDP, the five countries' GDP, Japanese CPI, the five countries' CPI, Japanese imports of tea amount $Q$, the yen exchange rate $\mathrm{EXj}$, the five countries of the currency exchange rate EX and Japanese total trade with the five countries. Dummy variable, $S_{1} S_{1 t}$ PLS enacted node, $\mathrm{t}>2003,=1 ; \mathrm{t}<2003$, $=0$. SPS $2 \mathrm{t}$, PLS implemented node, $\mathrm{t}>2006$, $=1 ; \mathrm{t}<2006,=0$.

From UN Comtrade Database and World Bank database, we collected since 1990 to 2013 code HS4 tea imported under the annual data, deducing CIF prices, since 1990 to 2013 at current dollars price calculation of Japanese GDP and five countries' GDP, countries in the official exchange rate EX, otal trade between Japan and the five countries G, Japanese demand for tea Q and each CPI of five countries.

In addition, as the base in 2010, using constant price, so as to weaken the exclusive data variance characteristics, for each of GDP, the official exchange rate EX, total trade between Japan and the five countries $G$ as well as Japanese demand for tea Q. Wherein, lnGDP represents GDP's logarithm, $\ln E X$ represents EX's logarithm, $\operatorname{lnG}$ represents G's logarithm, $\ln D$ represents D's logarithm, $\operatorname{lnCPI}$ represent CPI's logarithm.

Explanation of Parameters to be estimated. In Formula (5), the important parameters to be estimated including $\beta_{1}, \beta_{2}$ and $\beta_{3}$. $\beta_{1}$ means the impact on the price of tea imported from Japan promulgated PLS system. Sign of the parameter estimate is positive, indicating that the promulgation of PLS system will significantly improve the tea import prices. $\beta_{2}$ refers to the formal implementation of the PLS system affect tea imports to Japan, its estimated sign is negative, indicating that the implementation of PLS system and no further upgrade tea price of Japanese 
importing, but is suppressing the price; $\beta_{3}$ shows under the conditions of PLS the amount of tea imported affected the import prices. Theoretically $\beta_{3}$ to be estimated is negative, indicating that when PLS system is implemented, trade and price reverse change.

Regression results analysis. Next, using fixed-effect model analyzing formula (5), analyzing how PLS system affects prices. Part of the control variables, such as $\ln G, \ln G D P, \ln E X, \operatorname{lnCPI}$ etc. With the form of stepwise regression into the model, the corresponding regression analysis results meet expectations

According stepwise regression, there are five models in the analyzing. Converse model 5, parameter estimates of SPS1 and SPS2 both reject the null hypothesis, which are significantly non-zero at the $1 \%$ and $10 \%$ levels. As model 5 example, $\beta_{1}$ value of 0.11 , in line with the expectation, which means that there has a significant role in promoting after Japan enacted PLS System. The coefficient of $\beta_{2}$ is -0.08 , which is also consistent with the expectation, indicating that PLS system was formally implemented would significantly inhibited prices. The cross-term cannot accept $\mathrm{t}$ test, which the trade did not affect the price significantly after PLS system the implementation.

To test the robustness of the regression results above, our basic regression formula (5) were two forms of robustness test. First, take into account the impacton the lag problem of SPS, the first robustness test will lag SPS1 into the model; while taking into account changes between price and demand lag, the second test is robust tea imports lag $\mathrm{D}$ into the model. The robustness of the results of these two tests is consistent with earlier, which shows empirical results of this paper are robust.

\section{Summary}

By tea trade panel data of Japanese five main tea trading countries, analyzing the impact of imports on the Japanese tea prices for PLS system. The results showed that the promulgation of PLS system would significantly improve the tea import prices, the formal implementation of the PLS system would significantly inhibit the import price. Thus, the enactment and implementation phases PLS system, Japanese tea import prices overall showing trends ascending slightly prior to declining. This Price effect of PLS system provides a new scientific way to deal with SPS for foreign exporters enterprise. When Exporter companies face the foreign SPS measures could actively transfer the extra cost pass on export prices, and strive to the scientific coping SPS strategies that technological upgrading, cost transfer, price enhancing, exports to maintain.

\section{Acknowledgments}

This work was financially supported by the National Science Foundation for Distinguished Young Scholars of China (Grant No.711031667).

\section{References}

[1] Wilson, J. S. \& Otsuka, T. To Spray or not to Spray: Pesticides, Banana Exports, and Food Safety, J. Food Policy, 2006, 29(2): 131-146.

[2] Feenstra, R. Advanced International Trade, M. Princeton, N.J.: Princeton University Press, 2004.

[3] Fontagné, L., Mimouni, M. \& Pasteels J. M. Estimating the Impact of Environmental SPS and SPSon International Trade, J. Integration and Trade Journal, 2005, 28(19): 7-37.

[4] Anderson, James E. and Van Wincoop, Eric. Gravity and Gravitas: A Solution to the Border Puzzle, J. American Economic Review, 2003, 93(1): 170-192.

[5] Yue, C., Beghin J. and Helen H. J. Tariff Equivalent of Technical Barriers to Trade with Imperfect Substitution and Trade Costs, J. American Journal of Agricultural Economics, 2006, 88(4): 947-960. 